\title{
The development of abdominal aortic aneurysms in mice is enhanced by benzo(a)pyrene
}

\author{
Yong Zhang' \\ Kenneth S Ramos ${ }^{1,2}$ \\ 'Department of Biochemistry \\ and Molecular Biology, University \\ of Louisville School of Medicine, \\ Louisville, KY, USA; ${ }^{2}$ Center \\ for Genetics and Molecular \\ Medicine, University of Louisville, \\ Louisville, KY, USA
}

\begin{abstract}
Cigarette smoking has been strongly associated with abdominal aortic aneurysm (AAA), but the components of tobacco smoke involved in AAA have not been identified. Benzo(a)pyrene $(\mathrm{BaP})$ is an important constituent in cigarette smoke capable of induction of alterations strikingly similar to the pathological changes seen during AAA development. We therefore hypothesized that $\mathrm{BaP}$ exposure contributes to the development of AAA. In this study, C57/B6J mice were treated with vehicle, angiotensin II (AngII) (0.72 mg/kg/day), BaP (10 mg/kg/week), or the combination of AngII and BaP, for 5 weeks, and then examined for incidence of AAA and pathological changes of the aortic wall. Results showed that incidence of AAA formation in C57/B6J mice treated with BaP and AngII was significantly higher than that in AngII-treated mice ( 7 of 12 compared to 2 of 12). Further, five mice in the group treated with AngII/BaP and one in the group treated with AngII exhibited AAA rupture and hematoma. $\mathrm{BaP}$ caused macrophage infiltration, disarray of elastic lamella, and loss of vascular smooth muscle cells (VSMCs). We conclude that BaP aggravates AAA formation and rupture in C57/ B6J mice by promoting macrophage infiltration, degeneration of elastic lamella, and loss of VSMCs in the aortic wall.
\end{abstract}

Keywords: abdominal aortic aneurysm, benzo(a)pyrene, cigarette smoking, aorta, C57B/6J mice

\section{Introduction}

Abdominal aortic aneurysm (AAA) becomes increasingly common among the elderly (Bengtsson et al 1996; CDCP 2002). Rupture of AAA, a deadly complication of the disease, accounts for 15,000 deaths every year in the US (Kochanek and Smith 2004), and is ranked as the 13th most common cause of death in the US (Patel et al 1995). Lack of therapeutic drugs for the treatment of AAA is largely due to a poor understanding of the pathological mechanisms of this disease, a fact that justifies the urgent need for basic and clinical research on this disease.

Benzo(a)pyrene (BaP), a byproduct of combustion of tobacco, is an important component of cigarette smoke (Schmeltz et al 1974, 1975), and cigarette smoking has been strongly associated with AAA development (Wilmink et al 1999; Jamrozik et al 2000; Vardulaki et al 2000; Wanhainen et al 2005) and rupture (Chang et al 1997). Compared to nonsmokers, current smokers are, on average, about $8 \times$ more likely to have an AAA (Wilmink et al 1999; Jamrozik et al 2000; Vardulaki et al 2000; Wanhainen et al 2005), and ex-smokers are $4 \times$ more likely to succumb to this disease (Wilmink et al 1999; Jamrozik et al 2000). This suggests that one or more of the components present in cigarette smoke causes or aggravates AAA.

It has been estimated that the average intake of BaP is about $700 \mathrm{ng} /$ day for unfiltered cigarettes or $400 \mathrm{ng} /$ day for filtered cigarettes in smokers who consume a pack of cigarettes per day (NAS 1972). The exposure of smokers (a pack of cigarette per day) to similar compounds polycyclic aromatic hydrocarbons has been estimated to be 6 to $10 \mu \mathrm{g} /$ day (ATSDR 1995). As an important component of cigarette smoke, BaP trig- 
gers a variety of biological responses, such as infiltration of macrophage and related inflammatory reactions (Curfs et al 2004; Lecureur et al 2005), up-regulation of metalloproteinase (MMP) expression (Haque et al 2005), and activation of nuclear factor- $\kappa B$ (Pei et al 2002; Weng et al 2004). Importantly, all of these pathological changes are also observed in the process of AAA development. We therefore hypothesized that $\mathrm{BaP}$ exposure contributes to AAA formation.

Often used in AAA animal models, angiotensin II (AngII) induces AAA in apoE-deficient mice with incidence rates of about 90\% (Daugherty et al 2000; Deng et al 2003; MartinMcNulty et al 2003), and in C57/BL6J mice with much lower incidence rates but the same pathological changes within the aortic wall (Deng et al 2003). Considering that the high incidence rate of AAA in AngII-treated apoE-deficient mice leaves little room to examine the putative effects of $\mathrm{BaP}$ on the development of AAA, in the present study we elected to examine AAA in C57/B6J mice given AngII-infusion.

\section{Experimental methodology}

\section{Animals and treatment of Angll and $\mathrm{BaP}$}

C57/B6J mice (6 to 8 months old male) were purchased from The Jackson Laboratory (Bar Harbor, ME, USA) and housed in according to National Institutes of Health (NIH) guidelines for animal care and use. A subpressor dose $(0.72 \mathrm{mg} / \mathrm{kg} /$ day $)$ of AngII (Sigma, St. Louis, MO, USA) or an equivalent volume of saline was administered using an osmotic pump (Model\# 2004; Alzet, Cupertino, CA, USA), as described below. After calculating the desired concentration and preparing AngII solution, the pumps were filled with AngII saline solution and incubated in a $37^{\circ} \mathrm{C}$ water bath for 12 hours. Animals were anesthetized and skin in the mid-scapular area shaved and sterilized. A mid-scapular incision was made, and a pocket for the pump was created under the subcutaneous tissue. After inserting the pump into the pocket, the wound was closed with clips. BaP (Sigma) was dissolved in medium chain triglyceride oil (Mead Johnson Nutritional, Evansville, IN, USA) at a concentration of $2 \mathrm{mg} / \mathrm{ml}$. Mice were injected intraperitoneally with $\mathrm{BaP}$ at a dose of $10 \mathrm{mg} / \mathrm{kg}$ body weight or equivalent volume of oil once a week for 5 weeks. Current guidelines for use of biohazardous materials were followed when using $\mathrm{BaP}$.

\section{Harvesting and evaluation of aortas}

Following individual or combined treatments, the animals were sacrificed with $\mathrm{CO}_{2}$; and aortas were harvested and cleaned under a dissection microscope. The suprarenal segments of aortas (a length of $1 \mathrm{~cm}$ above the left renal artery) were imbedded in Tissue-Tek O.C.T. (Sakura Finetek Inc., Torrance, CA,
USA) embedding medium and frozen in liquid nitrogen. Five micrometer serial sections of the suprarenal aorta segments were prepared and stained with hematoxylin-eosin (HE) stain. Because of irregular shapes of the aortic rings, we measured the circumference, instead of diameter, of the rings for comparison among the experiment groups. The circumference (following the endothelial layer) of the aorta was measured with the aid of NIH Image J. The aortas with circumference increases equal to or greater than $50 \%$ of the average circumference ( $946 \pm 69$ micrometer) of the control mice were considered aneurysm formation. The difference in the incidences of AAA between AngII-treated mice and the mice treated with both AngII and BaP was examined by Fisher's Exact Test.

\section{Histological examination}

For paraffin-imbedding, animals were perfused through the left ventricle sequentially with $0.9 \%$ sodium chloride and with $10 \%$ paraformaldehyde solution. The aorta was removed and preserved in 10\% paraformaldehyde before processing for embedding. For frozen sections, each aorta was embedded in Tissue-Tek O.C.T. embedding medium and frozen in liquid nitrogen. Five micrometer serial sections of suprarenal aorta segments were prepared and stained with HE stain or elastic Van Gilson stain for histological evaluation of vascular structures.

\section{Identification of macrophages in the aortic wall by immunohistochemistry staining}

The serial frozen sections of the arteries were examined for macrophage infiltration using immunohistochemistry stain with the monoclonal F4/80 antibody against mouse macrophage (GeneTex, Inc. Cat\# GTX26640). The slides were thawed at room temperature for 20 minutes, and fixed with acetone for 10 minutes. After 30 minutes of treatment in the blocking solution (1\% gelatin in phosphate buffer solution [PBS]) at room temperature, tissue sections were incubated at room temperature with the diluted primary antibody (1:40) for 1 hour. Tissue sections were washed with PBS twice (5 minutes each) and incubated with 1 to 100 diluted anti-rat HRP-labeled secondary antibody (Jackson ImmunoResearch Lab. Inc., West Grove, PA, USA) for 30 minutes. The images of the stained tissue sections were recorded using a microscope. The extensity of macrophage infiltration was measured by the number of the positive cells per unit of area (0.01 square of millimeter). ANOVA was applied to test the statistical significance of the difference among three groups (control, AngII-treated, and BaP-treated). 


\section{Experimental results}

High incidence of AAA formation

and rupture in BaP/Angll-treated

C57/B6j mice

To answer the basic question of whether $\mathrm{BaP}$ has any impact on AAA formation, we treated four groups of C57/B6j mice (12 for each group) respectively with (1) medium chain triglyceride oil, a vehicle for $\mathrm{BaP}$ treatment, once a week, (2) $\mathrm{BaP}(10 \mathrm{mg} / \mathrm{kg}$ body weight, IP) once a week, (3) AngII $(0.72 \mathrm{mg} / \mathrm{kg}$ body weight/day with osmotic pump), or (4) the combination of AngII and BaP (with the same doses). The subpressor dose of AngII had minimal effects on mouse blood pressure. At the end of 5 weeks of treatment, aortas from the arch to just above the iliac bifurcation were dissected and exposed under a dissecting microscope. Tissue sections of the suprarenal segments (a length of $1 \mathrm{~cm}$ long above left renal artery) from all aortas were obtained and stained with HE stain. The circumferences of the aortic rings from the four experimental groups were measured using NIH Image $\mathrm{J}$, and shown in Table 1. The average circumference of the control mice was $946 \pm 69$ micrometers. The aortas with a circumference increased by $50 \%$ of the average circumference of the control mice, ie, more than 1417 micrometers, were considered as aneurysm formation.

The results showed that while AngII induced AAA in 2 of 12 treated mice, the combination of $\mathrm{BaP}$ and AngII caused a significantly higher incidence of AAA (7 of 12 animals)

Table I Circumferences (micrometers) of the aortas isolated from four experimental groups

\begin{tabular}{lllll}
\hline $\begin{array}{l}\text { Animal } \\
\text { ID\# }\end{array}$ & Control & Ang & BaP & Ang/BaP \\
\hline 1 & 887.65 & 1151.532 & 1153.686 & 1499.692 \\
2 & 1090.941 & 1489.89 & 896.985 & 1039.254 \\
3 & 907.341 & 1291.079 & 1096.475 & 1521.023 \\
4 & 1002.21 & 1510.573 & 995.901 & 1490.101 \\
5 & 964.861 & 1065.989 & 1086.9 & 1097.25 \\
6 & 872.238 & 1247.673 & 1201.32 & 1574.24 \\
7 & 899.346 & 1005.46 & 1192.557 & 1203.209 \\
8 & 990.461 & 1151.021 & 1095.535 & 1551.079 \\
9 & 1012.021 & 1223.104 & 951.669 & 1507.532 \\
10 & 897.452 & 1102.231 & 889.81 & 1312.361 \\
$I I$ & 968.241 & 995.94 & 1202.211 & 1185.018 \\
12 & 860.498 & 1198.245 & 1055.892 & 1601.145 \\
\hline
\end{tabular}

Note: The bolded numbers showed those circumferences of the aortas with AAA. Abbreviations: AAA, abdominal aortic aneurysm; Ang, angiotensin; $\mathrm{BaP}$, benzo(a)pyrene.
(Figure 1); Among them, one mouse in the group treated with AngII and five mice in the group treated with both AngII and $\mathrm{BaP}$ exhibited $\mathrm{AAA}$ rupture and hematoma formation (Figure 2). These results indicate that BaP treatment increased not only AAA incidence but also the probability of AAA rupture in C57/B6J mice. Histological analysis of the aortic wall showed severe damage to the medial layer, breakage of elastic lamella, and aortic rupture (indicated by arrow) in mice treated with both AngII and BaP (Figure $1 \mathrm{~A}$ ). The aortic wall at the location of rupture was significantly thinner, compared to other parts of the wall. This damage, coupled to thinning of the wall (broken arrows) was also observed in other parts of the aorta (Figure 1A).

\section{$\mathrm{BaP}$ causes damage to the arterial wall}

To examine the individual effects of $\mathrm{BaP}$ or AngII on the aortic wall, we isolated aortas from control, BaP-treated, and AngII-treated mice. Tissue sections were taken from these aortas and stained with hematoxylin-eosin. The results of HE-staining are shown in Figure 3. BaP or AngII alone caused disarray and degradation of the elastic lamella. The medial layers of the aortas from AngII- and BaP-treated groups were considerably thinner than those in control mice. Although the medial layer of aortas from BaP-treated mice was severely damaged, the adventitia of the arteries was thicker than that of AngII-treated mice, an indication of adventitial remodeling. The appearance of the cells with rounded-shaped nuclei in the walls of the aortas isolated from AngII-treated and BaP-treated groups, suggests infiltration of inflammatory cells, which was confirmed by the experimental result shown in Figure 4.

\section{BaP-induced macrophage infiltration into the arterial wall}

Macrophages in the aortic wall were detected by immunohistochemistry staining with macrophage F4/80 antibody (GenTex, Inc. Cat\# GTX26640). Macrophage infiltration within the aortic wall was quantified by counting the positively stained cells per area of 0.01 square millimeters in the aortic wall (Figure 4A). The results indicated that AngII or $\mathrm{BaP}$ treatment alone caused macrophage infiltration into the aortic wall, with more intensive macrophage infiltration shown in the aortas from BaP-treated mice (Figure 4B).

\section{Discussion}

The results of this study demonstrate that $\mathrm{BaP}$, an important component of cigarette smoke, promotes the AAA formation and rupture in C57/B6J mice (Figure 1 and 2). Etiologically, 
(A)

(B)
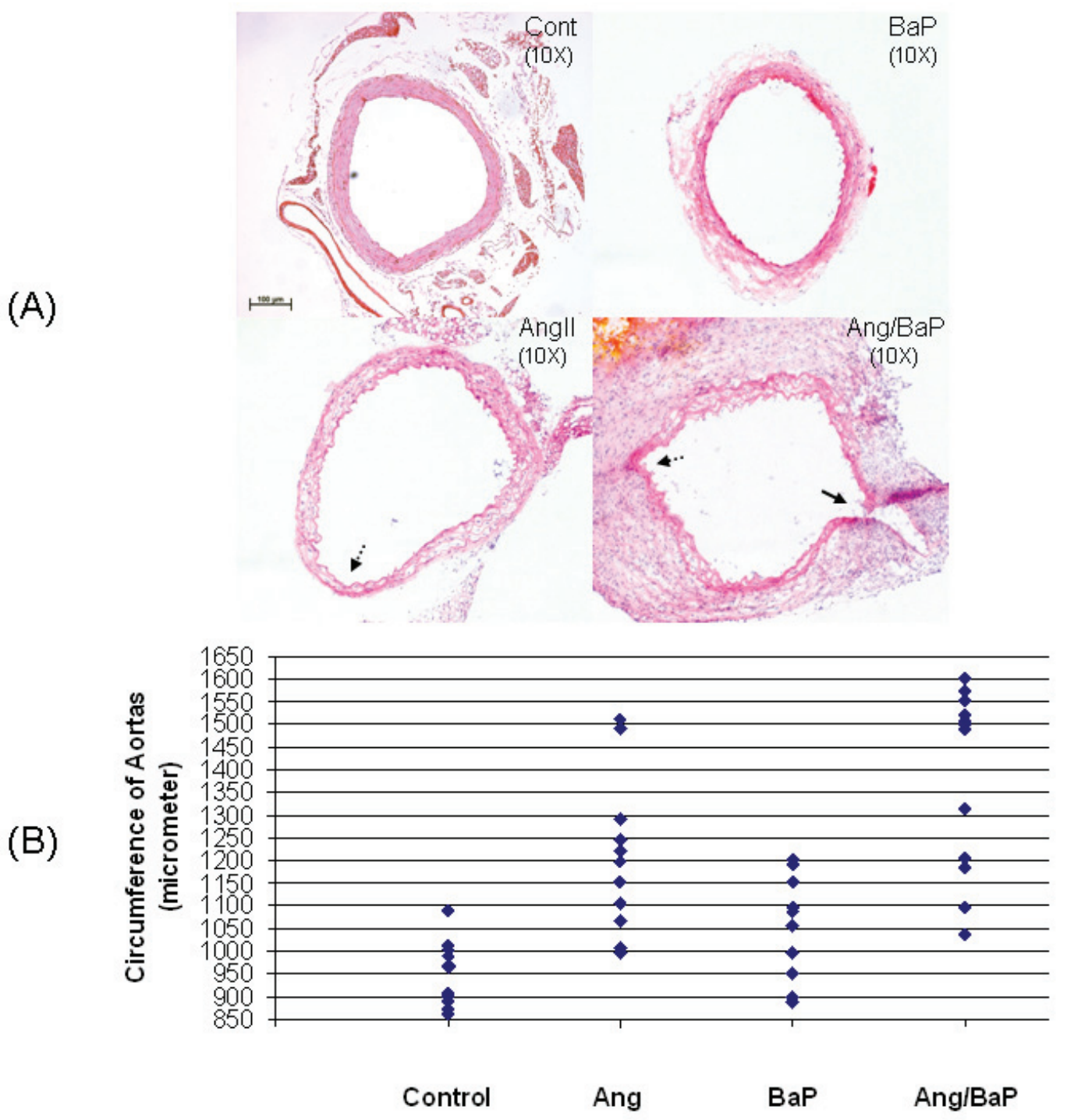

Figure I High incidence of AAA formation in C57/B6] mice treated with both Angll and BaP. Representative HE-stained tissue sections of suprarenal segments (I cm above left renal artery) of the aortas from control and treated mice were shown (A). We measured the circumference of aortic rings from four experimental groups using the computer program of $\mathrm{NIH}$ Image J.AAA was defined as circumferences that were increased by more than $50 \%$ of the average circumference in the control group $(946 \pm 69$ micrometers). Seven mice from the group treated with both Angll/BaP and two from the Angll-treated group showed AAA formation with circumferences greater than 1417 micrometer (B, each diamond represents a different mouse). Differences in the occurrence of AAA formation between the Angll-treated group and the group treated with both Angll and BaP was statistically significant $(\mathrm{P}<0.05)$. Histology of the aortic wall showed severe damage to the medial layer, breakage of elastic lamella, hematoma, and aortic rupture (indicated by the arrow) in the mouse group treated with both Angll and BaP (A). The aortic wall at the location of rupture was significantly thinner, compared to other parts of the aortic wall. A damaged and thinner aortic wall (broken arrows) was also observed in aortic rings harvested from mice treated with Angll and mice treated with both Angll and BaP.

Abbreviations: AAA, abdominal aortic aneurysm;Angll, angiotensin II; BaP, benzo(a)pyrene; HE, hematoxylin-eosin; NIH, National Institutes of Health.

AAA is considered a pathological consequence of the interaction between environmental factors and genetic traits. We have known for 30 years that cigarette smoking contributes to the formation and rupture of AAA (Alcorn et al 1996; Wilmink et al 1999; Rodin et al 2003). It is well established that the more and the longer a patient smoked, the greater the likelihood of AAA formation (Strachan 1991; Chang et al 1997; Blanchard et al 2000). There is no doubt that components of cigarette smoke contribute to AAA formation, but individual components have not yet been identified.
Among the many components of cigarette smoke, $\mathrm{BaP}$ causes unique biological effects consistent with the vascular pathology seen in individuals who smoke (Ramos et al 2007). The pathological process of AAA was characterized by infiltration and accumulation of macrophages in the arterial wall (Rubini et al 2001; Forester et al 2005), disruption of elastic lamella and deterioration of collagen networks (Thompson and Parks 1996; Daugherty and Cassis 2002), and loss of VSMC in the media (Lopez-Candales et al 1997; Thompson et al 1997). Excessive expression of matrix MMPs has been observed 

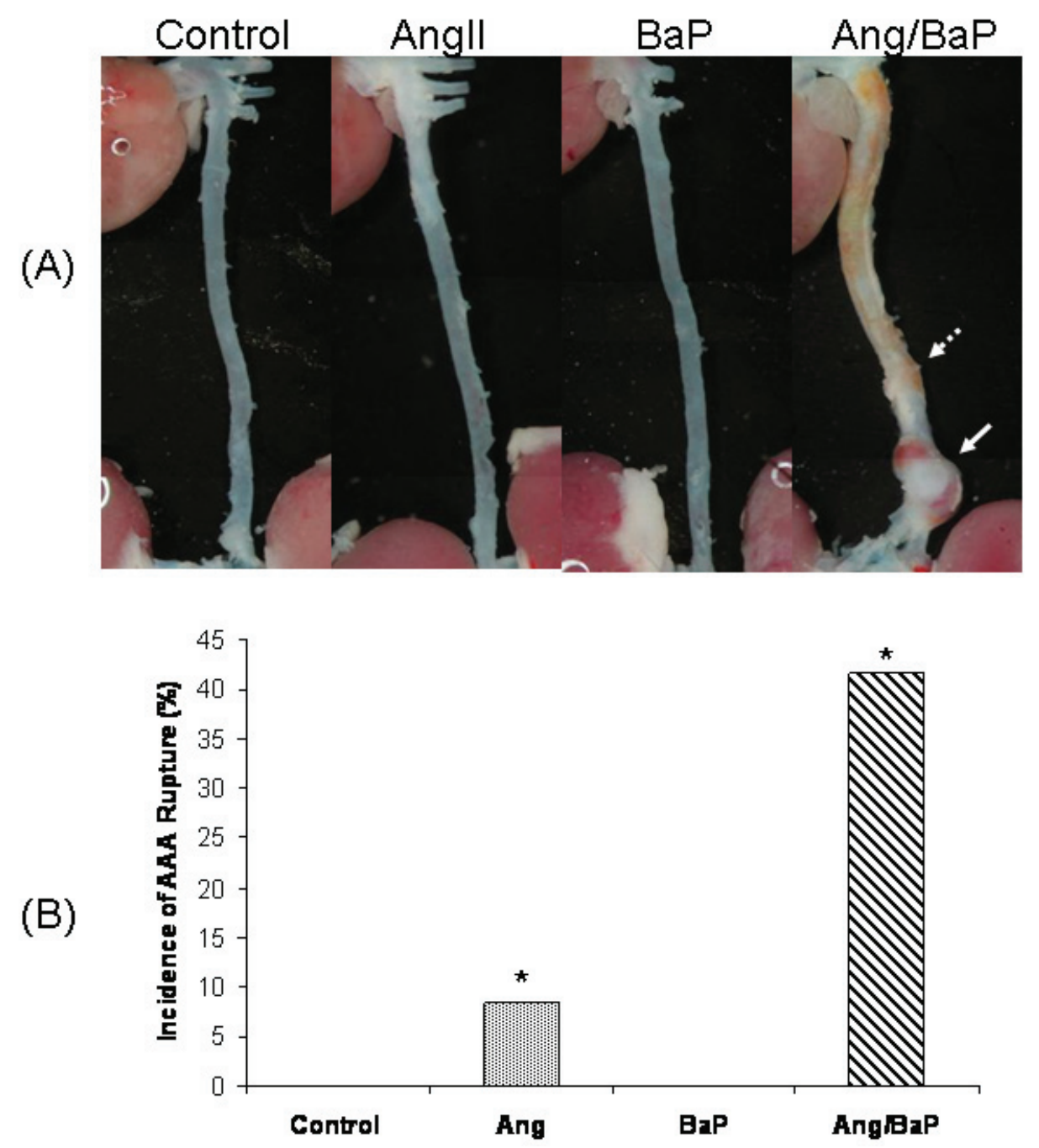

Figure 2 High incidence of AAA rupture and hematoma formation in C57/B6] mice treated with both Angll and BaP. Representative photomicrographs of aortic segments from heart to kidney, harvested from control and treated mice were shown (A). Five mice from the group treated with both Angll and BaP and one in the Angll-treated group showed AAA rupture and hematoma formation (solid arrow). No arterial rupture or hematoma formation was observed in the control group or in the group treated with $\mathrm{BaP}$ alone. In mice treated with Angll/BaP, the yellowish stain surrounding tissues (indicated by broken arrow) was tightly attached to the adventitial layer of the aorta (A). The difference in occurrence of AAA rupture and hematoma formation between the Angll-treated group and the group treated with both Angll and BaP was statistically significant $(P<0.05)(B)$.

Abbreviations: AAA, abdominal aortic aneurysm; Angll, angiotensin II; BaP, benzo(a)pyrene.

in AAA tissue samples (Pyo et al 2000; Goodall et al 2001; Longo et al 2002), a change believed to be responsible for the degradation of elastin and collagen and the AAA formation (Holmes et al 1996; Longo et al 2005). In these pathological events, nuclear factor- $\kappa \mathrm{B}$ plays a pivotal role by regulating macrophage migration and MMPs expression (Nakashima et al 2004; Parodi et al 2005). BaP induces infiltration of macrophages (Curfs et al 2004), up-regulation of MMP activities (Haque et al 2005), and activation of nuclear factor- $\kappa \mathrm{B}$ (Pei et al 2002; Weng et al 2004). BaP also suppresses collagen production of vascular endothelial cells and smooth muscle cells, that is similar to the effect of cigarette smoke extracts on the same cells (Raveendran et al 2004). All these observations suggest that BaP may be one of the important components in cigarette smoke that promote the development of AAA. Nevertheless, to our knowledge, no direct evidence has yet been presented that $\mathrm{BaP}$ contributes to the development of AAA. Using the well established mouse model of AngII-induced AAA, we demonstrate here at the first time the detrimental effect of $\mathrm{BaP}$ on the development of AAA in vivo. AngII has been known to cause AAA formation in hyperlipidemic mice (apoE-deficient) with high incidence rates (Daugherty et al 2000; Deng et al 2003; Martin-McNulty et al 2003). In C57/B6J mice, however, AngII-induced AAA formation is seen at considerably lower incidence rates (Deng et al 2003). The elevated incidence of AAA induced by combined treatment of C57/BB6J mice with AngII/BaP indicates a role for BaP in AAA formation. 


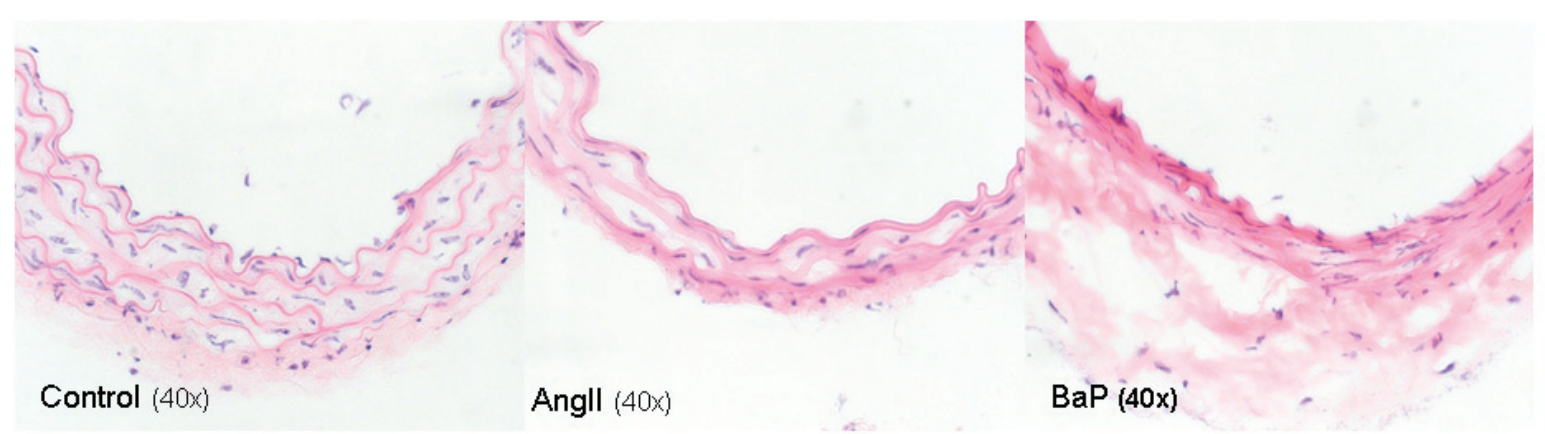

Figure 3 Damage of the arterial wall by Angll or BaP treatments. We show representative images of the aortic wall at the suprarenal segment of the aortas obtained from control, Angll-treated, and BaP-treated mice. Compared to control animals, the medial layer of aortas from Angll-treated mice and BaP-treated mice was shrunken; elastic lamella lost fine lines and instead degraded into loosely defined lines. These changes were particularly severe in aortas from BaP-treated mice, with fewer cells (VSMCs) seen in the medial layer. In adventitia, there were some cells with a rounded-shaped nucleus, resembling inflammatory cells.Although the medial layer of the aortas from BaP-treated mice was severely damaged, the adventitia of the arteries was thicker.

Abbreviations: Angll, angiotensin II; BaP, benzo(a)pyrene;VSMCs, vascular smooth muscle cells.

It is also important to note that $\mathrm{BaP}$ treatment increases the incidence of AAA rupture in mice (Figure 2). This might be, at least partly, account for the association between cigarette smoking and AAA rupture (Chang et al 1997).

To answer the question as to how $\mathrm{BaP}$ is involved in the development of AAA, we examined the individual effect of $\mathrm{BaP}$ or AngII on the biological structure of the aortic wall. Based on histological examination, we found that $\mathrm{BaP}$ alone caused macrophage infiltration and structural damage to the aortic wall, but no aneurysm formation in C57/B6J mice. The medial layer of the aortas from both the AngIIor BaP-treated mice was considerably thinner compared to

(A)

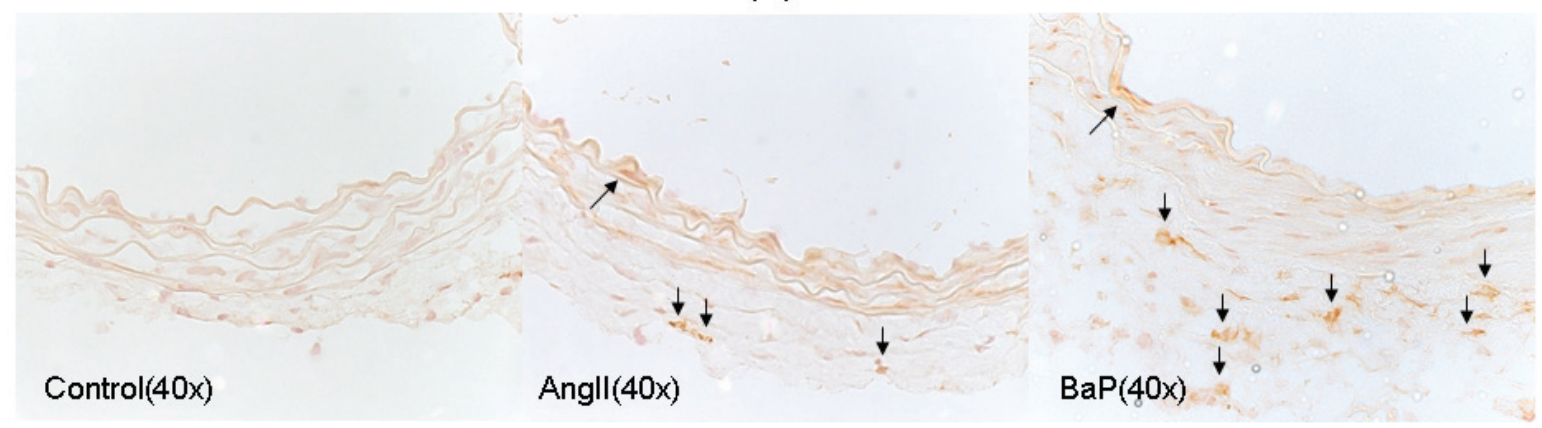

(B)

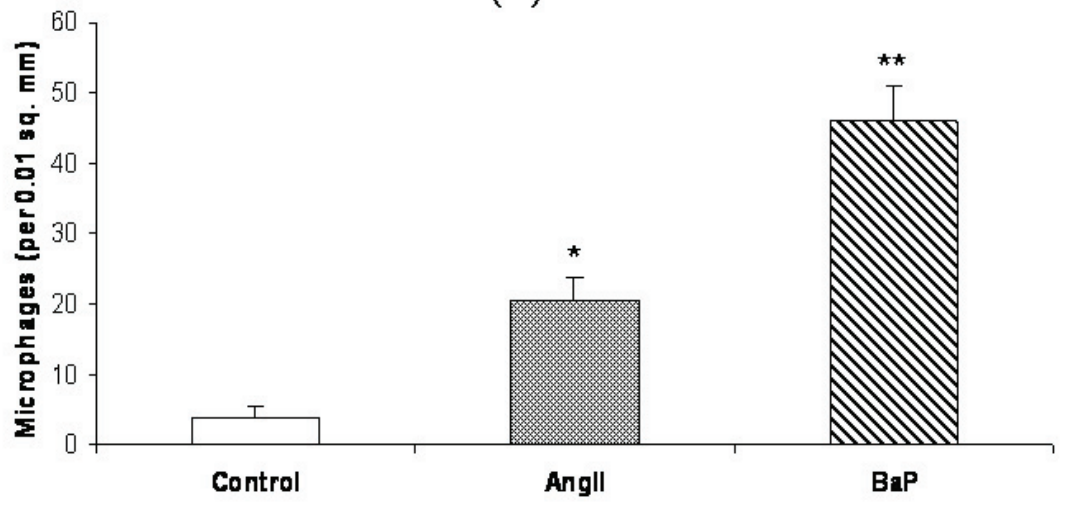

Figure 4 Macrophage infiltration into the aortic wall caused by Angll or BaP treatments. We present the images of immunohistochemical staining with macrophage F4/80 antibody of aortic sections from control,Angll-treated and BaP-treated mice. Macrophage infiltration within the aortic wall (brown staining) was quantified by counting positively stained cells per area of 0.01 square millimeters $(n=6)(B)$. The results show that both Angll and BaP caused macrophage infiltration into the aortic wall, but the response was more intense in BaP-treated mice.

Abbreviations: AAA, abdominal aortic aneurysm;Angll, angiotensin II; BaP, benzo(a)pyrene. 
aortas from control mice, apparently due to the degradation of elastin and collagen and loss of VSMCs (Figure 3). The appearance of round-shaped cells in the walls of the aortas isolated from AngII-treated and BaP-treated groups, suggests infiltration of inflammatory cells (Figure 3 ). This was confirmed by immunohistochemistry staining with antibody against mouse macrophage (Figure 4). This is consistent with the observation made by Curfs and colleagues (2004) showing that using a comparable dose of $\mathrm{BaP}(5 \mathrm{mg} / \mathrm{kg}$ for 12 to 24 weeks, total dose in range of 60 to $120 \mathrm{mg}$ per $\mathrm{kg}$ body weight). BaP treatment led to macrophage infiltration in the aortic wall of apoE-mutant mice (Curfs et al 2004). Although the medial layer of the aortas from BaP-treated mice was severely damaged, the adventitia of the arteries was thicker (Figure 3), a strong indication of adventitial remodeling. This explains why no AAA formation and rupture was observed in the BaP-treated group, even though the medial layer was severely damaged. However, when in combination with the effects of AngII, the damage caused by $\mathrm{BaP}$ led to higher incidences of AAA compared to those of AngII-treated mice. These results indicate that there are synergistic interactions between BaP and AngII in the development of AAA in C57/B6J mice. Further studies are needed to understand the molecular mechanism of this synergistic effect. It will be interesting to determine the effects of BaP, AngII, and $\mathrm{BaP} / \mathrm{AngII}$ on macrophage infiltration and the degradation of elastic lamella and collagen, at different stages of AAA development, and to understand the temporal relationship between the $\mathrm{BaP}$ and AngII effects, as well as their interaction during AAA development.

In summary, we report here that BaP causes disarray of elastic lamella, loss of VSMCs, shrinkage of the aortic wall, and infiltration of inflammatory cells, and increases the incidence of AAA formation and rupture in C57/B6J mice. BaP-induced damage to the aortic wall delineates the pathological mechanism by which this chemical agent enhances AAA development. These results shed light into the pathological mechanisms of AAA development.

\section{Disclosure}

The authors were supported by grant number NIH 5RO1 ES004849. The authors report no conflicts of interest in this work.

\section{References}

Alcorn HG, Wolfson Jr. SK, Sutton-Tyrrell K, et al. 1996. Risk factors for abdominal aortic aneurysms in older adults enrolled in The Cardiovascular Health Study. Arterioscler Thromb Vasc Biol, 16:963-70.
[ATSDR] Agency for Toxic Substances and Disease Registry. 1995. Toxicological Profile For Polycyclic Aromatic Hydrocarbons. U.S. Department of Health and Human Services, Public Health Service, Agency for Toxic Substances and Disease Registry: 273.

Bengtsson H, Sonesson B, Bergqvist D. 1996. Incidence and prevalence of abdominal aortic aneurysms, estimated by necropsy studies and population screening by ultrasound. Ann N Y Acad Sci, 800:1-24.

Blanchard JF, Armenian HK, Friesen PP. 2000. Risk factors for abdominal aortic aneurysm: results of a case-control study. Am J Epidemiol, 151:575-83.

[CDCP] Centers for Disease Control and Prevention. 2002. National Hospital Discharge Survey: 2000 Annual Summary With Detailed Diagnosis and Procedure Data. Accessed on March 10, 2008. URL: http://www.cdc. gov/nchs/data/series/sr_13/sr13_153.pdf.

Chang JB, Stein TA, Liu JP, et al. 1997. Risk factors associated with rapid growth of small abdominal aortic aneurysms. Surgery, 121:117-22.

Curfs DM, Lutgens E, Gijbels MJ, et al. 2004. Chronic exposure to the carcinogenic compound benzo[a]pyrene induces larger and phenotypically different atherosclerotic plaques in ApoE-knockout mice. Am J Pathol, 164:101-8.

Daugherty A, Cassis LA. 2002. Mechanisms of abdominal aortic aneurysm formation. Curr Atheroscler Rep, 4:222-7.

Daugherty A, Manning MW, Cassis LA. 2000. Angiotensin II promotes atherosclerotic lesions and aneurysms in apolipoprotein E-deficient mice. J Clin Invest, 105:1605-12.

Deng GG, Martin-McNulty B, Sukovich DA, et al. 2003. Urokinase-type plasminogen activator plays a critical role in angiotensin II-induced abdominal aortic aneurysm. Circ Res, 92:510-17.

Forester ND, Cruickshank SM, Scott DJ, et al. 2005. Functional characterization of T cells in abdominal aortic aneurysms. Immunology, 115:262-70.

Goodall S, Crowther M, Hemingway DM, et al. 2001. Ubiquitous elevation of matrix metalloproteinase-2 expression in the vasculature of patients with abdominal aneurysms. Circulation, 104:304-9.

Haque M, Francis J, Sehgal I. 2005. Aryl hydrocarbon exposure induces expression of MMP-9 in human prostate cancer cell lines. Cancer Lett, 225:159-66.

Holmes DR, Petrinec D, Wester W, et al. 1996. Indomethacin prevents elastase-induced abdominal aortic aneurysms in the rat. J Surg Res, 63:305-9.

Jamrozik K, Norman PE, Spencer CA, et al. 2000. Screening for abdominal aortic aneurysm: lessons from a population-based study. Med J Aust, 173:345-50.

Kochanek KD, Smith BL. 2004. Deaths: preliminary data for 2002. Natl Vital Stat Rep, 52:1-47.

Lecureur V, Ferrec EL, N'Diaye M, et al. 2005. ERK-dependent induction of TNFalpha expression by the environmental contaminant benzo(a)pyrene in primary human macrophages. FEBS Lett, 579:1904-10.

Longo GM, Buda SJ, Fiotta N, et al. 2005. MMP-12 has a role in abdominal aortic aneurysms in mice. Surgery, 137:457-62.

Longo GM, Xiong W, Greiner TC, et al. 2002. Matrix metalloproteinases 2 and 9 work in concert to produce aortic aneurysms. $J$ Clin Invest, 110:625-32.

Lopez-Candales A, Holmes DR, Liao S, et al. 1997. Decreased vascular smooth muscle cell density in medial degeneration of human abdominal aortic aneurysms. Am J Pathol, 150:993-1007.

Martin-McNulty B, Tham DM, da Cunha V, et al. 2003.17 Beta-estradiol attenuates development of angiotensin II-induced aortic abdominal aneurysm in apolipoprotein E-deficient mice. Arterioscler Thromb Vasc Biol, 23:1627-32.

Nakashima H, Aoki M, Miyake T, et al. 2004. Inhibition of experimental abdominal aortic aneurysm in the rat by use of decoy oligodeoxynucleotides suppressing activity of nuclear factor kappaB and ets transcription factors. Circulation, 109:132-8.

[NAS] National Academy of Sciences; Committee on Biologic Effects of Atmospheric Pollutants. 1972. Particulate Polycyclic Organic Matter. Washington, DC: National Academy of Sciences (National Research Council). 
Parodi FE, Mao D, Ennis TL, et al. 2005. Suppression of experimental abdominal aortic aneurysms in mice by treatment with pyrrolidine dithiocarbamate, an antioxidant inhibitor of nuclear factor-kappaB. J Vasc Surg, 41:479-89.

Patel MI, Hardman DT, Fisher CM, et al. 1995. Current views on the pathogenesis of abdominal aortic aneurysms. J Am Coll Surg, 181:371-82.

Pei XH, Nakanishi Y, Inoue H, et al. 2002. Polycyclic aromatic hydrocarbons induce IL-8 expression through nuclear factor kappaB activation in A549 cell line. Cytokine, 19:236-41.

Pyo R, Lee JK, Shipley JM, et al. 2000. Targeted gene disruption of matrix metalloproteinase-9 (gelatinase B) suppresses development of experimental abdominal aortic aneurysms. J Clin Invest, 105:1641-9.

Raveendran M, Senthil D, Utama B, et al. 2004. Cigarette suppresses the expression of P4Halpha and vascular collagen production. Biochem Biophys Res Commun, 323:592-8.

Rodin MB, Daviglus ML, Wong GC, et al. 2003. Middle age cardiovascular risk factors and abdominal aortic aneurysm in older age. Hypertension, 42:61-8.

Rubini P, Bonati L, A. Parolari A, et al. 2001. [Inflammatory abdominal aortic aneurysms]. Minerva Chir, 56:287-98.

Schmeltz I, Hoffmann D, Wynder EL. 1974. Toxic and Tumorigenic Agents in Tobacco Smoke. Trace Substance Environment Health 8, Symposium.
Schmeltz I, Hoffmann D, Wynder EL. 1975. The influence of tobacco smoke on indoor atmospheres. Prev Med, 4:66-82.

Strachan DP. 1991. Predictors of death from aortic aneurysm among middleaged men: the Whitehall study. Br J Surg, 78:401-4.

Thompson RW, Liao S, Curci JA. 1997. Vascular smooth muscle cell apoptosis in abdominal aortic aneurysms. Coron Artery Dis, 8:623-31.

Thompson RW, Parks WC. 1996. Role of matrix metalloproteinases in abdominal aortic aneurysms. Ann N Y Acad Sci, 800:157-74.

Vardulaki KA, Walker NM, Day NE, et al. 2000. Quantifying the risks of hypertension, age, sex and smoking in patients with abdominal aortic aneurysm. Br J Surg, 87:195-200.

Wanhainen A, Bergqvist D, Boman K, et al. 2005. Risk factors associated with abdominal aortic aneurysm: a population-based study with historical and current data. J Vasc Surg, 41:390-6.

Weng MW, Hsiao YM, Chen CJ, et al. 2004. Benzo[a]pyrene diol epoxide up-regulates COX-2 expression through NF-kappaB in rat astrocytes. Toxicol Lett, 151:345-55.

Wilmink TB, Quick CR, Day NE. 1999. The association between cigarette smoking and abdominal aortic aneurysms. J Vasc Surg, 30:1099-105. 